\title{
EL GALATEO DE GIOVANNI DELLA CASA TRADUCIDO POR DOMINGO DE BECERRA
}

El tratado de Giovanni delia Casa sobre los buenos modales pasó a España con el nombre de Galateo español en la adaptación de Gracián Dantisco ${ }^{1}$. También hubo versión directa al castellano, hecha para una de esas ediciones plurilingües que embellecieron con gracia cosmopolita la cultura francesa en los albores del grand siècle. Dicha traducción se conserva en un minúsculo tomito cuyo frontispicio anuncia el título a la par que el contenido: Le GALATEE | premièrement composé en Italien par $I$. | de la Case, depuis mis en François, La-|tin et Espagnol par diuers auteurs. | Traicté tres utile et tres necessaire, pour bien dres-ser une jeunesse en toutes manieres et façons | de faire louables, bien reçues et approuuees par | toutes gents d'honneur et de vertu: et propre| pour ceux, qui non seulement prennent plaisir | en la langue Latine, mais aussi aux trois vulgaires qui en sont deriuées. [Viñeta con lema: QVOD TIBI FIERI NON VIS ALTERI NE FECERIS] PAR IEAN DE TOVRNES $\mid$ M.D.XCVIII.

Este pequeño volumen de 2 hs. +459 páginas en $16^{\circ}$ se lo dedicaba el conocido impresor lionés Juan de Tournes a un ahijado suyo, para edificar sus nueve añillos con los preceptos de Monseñor della Casa en cuatro idiomas ${ }^{2}$. El éxito de la edición lo prueban dos reimpresiones, una de 1609 y otra de $161_{5}$, en las cuales se añadió, con raro esfuerzo tipográfico, una traducción alemana, apaisando la versión latina debajo de las cuatro columnas de los textos en lenguas modernas ${ }^{3}$.

1 La fecha de la primera edición del Galateo español que me consta con seguridad por hallarse ejemplar en la B. N. M. es 1598 (Lisboa), o sea un año antes de la impresión del tomito que aquí nos interesa. De todos modos, entre la versión directa y la adaptación no hay relación alguna. Sobre ésta puede verse mi ensayo de próxima publicación en el $B R A E$.

2 Que yo sepa, existen ejemplares en la B. N. M. (cuatro), la B. N. P., el British Museum, la Folger Library de Washington (que es el que yo he empleado), la Universidad de Pennsylvania, Harvard y otras universidades norteamericanas.

${ }^{3}$ El frontispicio de estas reimpresiones lleva el título de la obra casi en idénticos términos que la edición anterior. Véase el de la ed. de 1609 , que he consultado en la Biblioteca de la Universidad de Columbia (hay otro ejemplar en la de Harvard): LE GALATEE, | premierement composé en Italien par I. | de la Case, et depuis mis en François, Latin, Allemand, et Espagnol Traité... [idéntico hasta vulgaires] qui pour se iourd'huy sont les plus prisés. [Viñeta con 
El aprendizaje de los idiomas iba parejo con la educación de los modales ${ }^{4}$.

La versión que aquí nos interesa es la castellana, o sea, para citar el título que figura en el frontispicio interior, el Tratado de M. Iuan de la Casa. En el qual sò la persona de vn viejo idiota que enseña à un muchacho suyo se razona de los modos que se deuen guardar o huir en la humana conuersaçion, llamado Galatheo, o Tratado de costumbre, traduzido de la lengua Toscana en Castellana por el Doctor Domingo de Bezerra.

De este Doctor Becerra, a quien se nombra como autor de la versión castellana, no conozco ningún otro escrito, pero por la versión misma puede afirmarse que, si vivía en Francia, conservó el dominio de su idioma nativo. Su traducción es independiente de la francesa y de la latina ${ }^{5}$. Está hecha con fidelidad, pericia y hasta elegancia, sin apocamiento ante las dificultades de un texto desigual en el estilo, repleto de citas y alusiones a autores italianos, inteligible en parte sólo con referencia a expresiones usadas en Italia ${ }^{6}$. Sin embargo, no se puede atribuir a Becerra una unidad de criterio y una pericia de estilo que dieran a su obra esa congruencia interior que tanto nos admira en la versión del Cortesano. Becerra cambia de punto de vista (compárese "questo presente Trattato", traducido como "este gracioso Tractado" en la p. 45, con "en nuestra lengua toscana", p. 265), y vacila entre el intento de atraer el original hacia su propio idioma

el mismo Iema] a Geneue, | Par iean de Tovrnes | MDC.IX. 7 hs. + 619 pp. en $16^{\circ}$. Puede ser que la indicación del lugar, que no aparece en la primera edición y está en caracteres distintos, se haya impreso a mano. La edición de 1615 (que no he visto) lleva el pie de imprenta "A Montbeliard, Par Iaqves Fevillet. 1615". El señor R. E. Stoddard, de la Biblioteca de la Universidad de Harvard, me informa que en el ejemplar que allí se conserva, el "A Montbeliard" se ha borrado, imprimiéndose a mano en su lugar "A Geneue". Los preliminares son idénticos en ambas ediciones: se ha omitido la dedicatoria de Tournes, y se han introducido unos resúmenes en francés, latín y alemán y un epigrama latino.

4 Además de la edición de Juan de Tournes (en la Folger Library) he visto otra bilingüe del Galateo (en italiano y francés, impresa también en León de Francia, en 1573), dedicada por Alessandro Marsili a Bartolomeo Arnolfini. La versión francesa es distinta de Ia contenida en nuestro tomito. También del Cortegiano se hizo edición bilingüe en italiano y francés (París, N. Bonfons, $\mathbf{1 5}^{\mathbf{8} 5)}$, de la cual se conserva un ejemplar en la Newberry Library de Chicago (adquirido en 1946).

5 Sólo he notado una curiosa coincidencia en las expresiones derramasolazes (p. 83) y trouble-repos, que resumen con eficacia Ia frase italiana "tengono in continua tribolazione tutta la compagnia"; escabelo 215 por panchetta (fr. scabelle) no llama la atención por tratarse de término ya naturalizado en España en la Edad Media. En cambio, seruieta 425 por touagliola (fr. serviette) debe de ser galicismo.

6 Sólo en la p. 295 he notado que Becerra omite dos párrafos sobre las palabras más apropiadas y las demasiado locales (en el texto ital. desde "significazione" hasta "Niun può adunque"). 
(por ejemplo en la cita de palabras reprobadas ${ }^{7}$ o en la elección de nombres propios en las partes dialogadas ${ }^{8}$ ) y el propósito de hacer un trasunto fiel de la obra de Della Casa. A veces interviene con un aditamento propio, "Y para que veas el caso..." (p. 37), otras se apoya excesivamente en el término italiano. La sujeción al original es particularmente sensible en los períodos largos del Galateo, donde las reflexiones se amontonan y se entrecruzan en forma de incisos. Becerra tiende a conservar los nexos de relativo ${ }^{9}$, no corta los períodos, y aun pone a veces coma en vez de un signo de puntuación más terminant $\mathrm{e}^{10}$, todo lo cual suele hacer fatigosa la lectura de esta traducción española. Pero de la traducción en su conjunto puede decirse que se amolda a la sintaxis castellana: Becerra cambia casi siempre el orden de las palabras, pone el adjetivo en el lugar que le corresponde en castellano (cf. "le lacrimose favole": "las fábulas dolorosas", p. 123), y a veces hasta resuelve la trabazón intrincada de las oraciones de Della Casa ${ }^{11}$.

No poco de lo que hemos dicho acerca de Juan Boscán como traductor ${ }^{12}$ podría repetirse del presente, y menos ilustre intérprete, en cuanto a la sintaxis y orden de las palabras. Si nos fijamos luego en las palabras mismas, hemos de reconocer que no ha pasado en balde medio siglo. Prueba de ello -y no de las menos sintomáticas- es la abundancia de superlativos aun donde no los pide el original (stomachevole: asquerosissima, p. 55; "qualquier difficultissima [!] y suttilissima question", p. 155). La proporción de palabras cultas es asimismo bastante mayor que la que encontramos en la mencionada versión (me refiero a voces como consorçio 13, fastidio 101, fastidioso 31,

7 Donde Della Casa prefiere ventre al dantesco epa, Becerra sugiere como voces más aceptables vientre y barriga (p. 287), y admite pança si fuere del "lenguaje de tu tierra" 291. Como palabras vitandas por anticuadas cita home, maguer y erguido (291: recuérdese también a Juan de Valdés: "por levantar se solía dezir erguir", Diál. de la leng., ed. Madrid, 1946, p. 110). Bajo la rúbrica de las palabras apropiadas a cada cosa escribe "mas propriamente diremos a la carne gorda del puerco lardo que no gordura y la lengua del agua que no el canto [!], y la orilla del paño, que no el cabo del paño, y los ojos zarcos, que no los ojos azules" 295 .

8 Véase el Periquito y la Francisquita de la p. 127.

9 El nexo de relativo, huelga recordarlo, es habitual también en la prosa castellana ya desde Alfonso el Sabio, pero se usaba -y se usa- más parcamente que en italiano. Becerra se amolda en esto al original, aunque a veces sin fijarse bien en la función del relativo; cf. en la p. 135 un a cui traducido por y que.

10 Cf., por ejemplo, la p. 343. La puntuación del texto italiano en la edición de Tournes es la (abundantísima) de Erasmo Gemini, primer editor de las Rime et prose (Venecia, 1558).

11 Esto es especialmente evidente en los incisos. Cf., por ejemplo, "basciandosi le mani come se essi le hauessero a guisa di sacerdoti, sacrate": "besándose las manos como si las tuuiessen consagradas como saçerdotes" (p. 163). Otros ejemplos pueden verse en mi estudio sobre el Galateo español.

12 Cf. Castiglione y Boscán: el ideal cortesano en el Renacimiento español (Estudio léxico-semántico), Madrid, 1959. 
113 , ignominioso 245 , imperar 95 , nociuo 175). El empleo de términos como apetitosamente 423, arengar 327 , enigma 291 , extravagante 389 , friuolo 115,225 , plagar por "plagiar" 21 , superabundante 20, 211,213 , thema [de conservación] 115, colocan a nuestro traductor muy a la cabeza en la documentación de dichas voces (cf. el $D C E C$ ).

A estos términos, que se hallan todos, menos ignominioso, en correspondencia con sus homónimos italianos, podrían añadirse otros como acariçiar 203, caricia 105, 107, 217, doméstico 103 (y passim); domestiqueza 71 , novela 275 , recamo 345 , saltan banco 427 , risada $45^{1}$, que podemos calificar más resueltamente de italianismos porque ya han sido señalados y documentados como tales, para no hablar de los términos italianos que Becerra traslada simplemente a su texto: madona 283 , miser $117^{13}$. Influencia extranjera denotan también dolenza 318, eleganza 327 y sobre todo usanza 163,171, 179 (y passim). Claro es que cuando hallamos disforme por difforme 333, "ceremoniosas personas" 215 junto a "ceremoniose persone", "llámanse patrones" 161 junto a "chiamarsi padroni", remisamente 153 junto al homónimo rimessamente, "los términos de Napoles señoriles y pomposos" 191 calcado a la letra del original, o valeroso 89 , que no cambia ni en un ápice el adjetivo italiano, no podemos menos de pensar en una influencia de este último idioma, aunque haya antecedentes españoles para todas esas voces. Si no cambia la forma, se enriquece el contenido, o al menos se intensifica la influencia mutua de palabras ya existentes por hallarse juntas en nuevos contextos ${ }^{14}$.

$¿$ Ha de deducirse por ende que Becerra fuera "neologista”? Lo fue moderadamente, según los cánones de su época. Faltan en su versión algunos italianismos y préstamos directos del italiano que hallamos en el Galateo español de Gracián Dantisco, como adormentar, bufón, poltrón, refutar (por rehusar), o que se hallan en los diccionarios, como facoleto, mientras que Becerra usa el castizo lien-

13 Véase J. Terlingen, Los italianismos en español desde la formación del idioma hasta principios del siglo xvii, Amsterdam, 1943, pp. 349 (domestiqueza), 101 (saltimbanco), 300 (madona), 372 (miser). Cf. también el DCEC, s. vv. caro y recamar.

14 Creo que en el estudio de los "italianismos", o mejor dicho de la influencia ejercida por el italiano en el español o viceversa, hay que fijarse sobre todo en el enriquecimiento o desviación semántica de las palabras de contenido ético y social. En el caso de las palabras corrientes, por el contrario, no hay que dejarse llevar a error por diferencias actuales, sino verlas en su desarrollo histórico. Así cuando Becerra escribe "gastan la conversaçion" con el sentido que hoy conserva el italiano guastare, no hay que pensar en un italianismo (cf. el $D C E C$ ). Otro caso es el de las palabras que, procediendo del mismo origen, han tenido distinto desarrollo en los dos idiomas, como blasphemare $>$ it. biasimare, esp. pop. lastimar, cult. blasfemar. El cultismo creo que se introdujo por adhesión al latín bíblico y eclesiástico, donde anteriormente se había dicho "denostar a Dios". Puede ser que la yuxtaposición biasimare (blâmer) - blasfemar haya inducido a emplear este término en contextos no religiosos, según se ve en esta versión de Becerra: biasimato: burlado y blasfemado $20_{5}$. 
ço de nariçes 61,459 o lenzuelo 35 . Una sola vez emplea el italianismo beffa ("hazer beffas de los agenos" 153), pero luego traduce beffa como burla 155, dándose cuenta seguramente, como más tarde Covarrubias, de que beffa era "palabra toscana".

No es fácil determinar la conciencia lingüística de estos escritores de los siglos xvi y xvn, que actuaban en un ambiente que podríamos llamar de bilingüismo cultural. Si Becerra escribía en Francia, se hallaba bajo la doble presión del término italiano y del italianismo francés (piénsese en caresse, civil). Sin embargo, no cabe duda de que se esforzó también por hallar términos propios en castellano. Véase cómo explica ritroso (adjetivo que el traductor francés deja en italiano): "obstinado y (hablando más propiamente) reuesado" (p. 99), y ritrosia: "esta reuesada condición" (ibid.).

Becerra maneja con soltura un caudal muy abonado de palabras y expresiones castizas. Citaré algunos ejemplos que podrían estar sacados de la versión del Cortesano: astratto: transportado y pensativo 107; "vezzosi modi": "modos y tenores blandos y regalados" 1 13 ; "uomini costumati": "hombres corteses y de buenas prendas" 175 ; teneri e arrendevoli: blandos y correosos 361 . Como la de Boscán, su versión tiende a ser analítica: stomachevole: "que rebuelbe el estómago" 55, rotto: "hecha pedazos" 133 , y suele completar la descripción desdoblando los términos: "... non si contegnoso [el andar] come una femina o come una sposa": "con tanta grauedad como vna matrona o como vna esposa que lleuan a uelar" 417; "non piace": "no agrada al otro, ni le haze buen estómago" 431 .

El desdoblamiento, característica constante de la prosa castellana ya desde Alfonso el Sabio, tiene un valor rítmico y retórico (arredi: arreos y ornamentos 15 ), un valor descriptivo ("soave sapore": "gusto suave y sazonado" 455) y explicativo (appetito: apetito y antojo 79, 283). A medida que se admiten más palabras cultas y rebuscadas, crece la frecuencia de su empleo, hasta que, en la versión de Domingo de Becerra, el desdoblamiento se hace casi continuo, bien sea que la palabra más abstracta o insólita vaya delante (aspera: aspera y terrible 13; appetito: apetito y antojo 79), o bien, como sucede más a menudo, que se coloque en segundo lugar (eccitare: despertar y conciliar 11 ; incitano: mueuen e incitan 11 ; "di minor condizione": "de menor estofa y condición" $7 \mathrm{l}$ ).

Aun en los trueques de palabra a palabra se nota cómo el desdoblar o, casi diríamos, el desentrañar su sentido dándoles mayor relieve fonético y morfológico produce efectos significativos para la diferencia entre el español y el italiano. En este último basta un morfema mínimo, una s-, para hacer negativo el concepto. En español el mismo papel negador lo desempeña el prefijo des-, preferido por necesidad fonética, y quizá también por ser signo lingüístico más perceptible y significativo; prueba de ello es que las mismas funcio- 
nes las desempeña a veces el adverbio mal. Véanse algunos ejemplos: sconvenevole: desconveniente 87, desmesurado y desacordado 229; sconcio: desmesurado 119 , descompuesto 389 ; scostumato: mal habituado 119; sformato: mal agestado 247; difforme: disforme y mal tallado. Recuerdo un maldigno por "indigno" ya en Berceo (Duelo, 171). En el Galateo, donde tantos conceptos negativos piden una expresión equivalente en español, los compuestos con mal son tan frecuentes que sirven para caracterizar el estilo del traductor, y constituyen un aspecto más de la ampliación y desdoblamiento que impone el original. Baste un ejemplo: bizzarri, ritrosi e strani: mal contentadizos y estrañamente mal acondicionados 85 .

$\mathrm{Si}$, por un lado, nuestro traductor se adhiere con fidelidad al original y se hace -aunque moderadamente- receptor de italianismos, por otro deja bastante holgura a la expresión castellana para que su obra pueda considerarse como un medio fehaciente de comparación semántica. Volviendo una vez más a mis observaciones acerca del Cortesano, subrayaré que también en el Galateo hallamos caballero en vez de gentiluomo $(41,129,168,191,193,427)$, con clara delimitación de este término dentro de una jerarquía inferior ("i nobili servitori": "los pages y gentiles hombres" 55). Esta preferencia por caballero no sólo frente a gentiluomo sino también al gentilhomme de la traducción francesa, es una prueba más de esa continuidad cultural y apego a la tradición que tantas veces se han puesto de relieve como características de España.

Por otra parte, la influencia de Italia se hace sentir -aun independientemente del contenido de la obrita de Della Casa- en el empleo que hace Becerra de dos voces, cortesano y civil: "costumato e piacevole e di bella maniera": "agradable y de amables y civiles costumbres" 5; "costumato gentilhuomo": "bien morigerado, discreto y cortesano" 17; "costumati huomini e scientiati": "hombres muy discretos, ciuiles y cortesanos" 41 (cf. 331); "doue costumati huomini fossero": "donde viuiessen hombres de buenas y ciuiles costumbres" 55 (cf. 229, 259). Cuando Becerra traduce $i$ gentilhuomini como "los cortesanos y discretos hombres" 331 , o il gentile como "el hombre cortesano y bien acostumbrado" 405 , nos percatamos de que el ideal de Castiglione no se había propagado en balde. La alusión al autor del Cortesano es casi explícita cuando el traductor vierte la referencia de Della Casa a "altri trattati, distesi da troppo migliori dettatori e maestri" con "haviendo desta materia otros tratados bien estendidos de muy mejores cortesanos y maestros que yo" 267 .

Por otra parte, el frecuente empleo de ciuil (hasta en la forma negativa inçiuil) constituye un cambio notable con respecto al léxico de Boscán ${ }^{15}$. Aunque no tenga un antecedente directo y específico en el Galateo (y tampoco en el Cortegiano), puede explicarse por la

\footnotetext{
15 Cf. Castiglione y Boscán, op. cit., t. 1, p. 112.
} 
insistencia en la civile conversazione y los modi civili de las letras italianas del Renacimiento. En Francia y en Inglaterra la influencia moral y social de Italia se delata justamente por la adopción constante de las dos palabras civile y cortegiano ${ }^{\mathbf{1 6}}$.

La falta de diccionarios especializados ítalo-españoles para el Cinquecento puede suplirse con la atenta lectura de versiones como la de Domingo de Becerra. A fines del siglo ya no hay tanteos en el traslado de bellezza $(267,387,395)$ y de bello, aunque en esto también hallamos vacilación entre el traslado más castizo ("alcuna cosa bella": "alguna cosa galana y nueua" 271) y la voluntad de adherirse al original tanto en el léxico como en el estilo ("gli altri costumi di lui belli e misurati": "las otras sus bellas y mesuradas costumbres" 403 ).

La dificultad real consiste en traducir otras palabras favoritas de Della Casa, como piacevole, y más aún leggiadro, vago y avvenente, que -además de ser de buena cepa boccaccesca- se adecúan mejor que bello a la naturaleza de los ideales de nuestro Monseñor. En la versión de Becerra quiero señalar sobre todo las palabras hacia las cuales gravita el vocabulario. Piacevole le sugiere en la mayoría de los casos el adjetivo correspondiente agradable (cf. 11, 14, 42, 46, 100 y passim), pero con un significativo desvio hacia una voz que se hace cada vez más frecuente en esta época, gusto: "piacevoli ragionamenti": "pláticas de gusto y contento" 45. En cuanto a avvenente, no sé si el traductor comprendería su verdadero significado; vierte libremente, sacrificando toda apreciación estética: "l'essere avvenente e costumato": "el ser auisado, ciuil y de corteses costumbres" 7. En cuanto a leggiadro y vago, es patente la tendencia a traducir dichos términos con referencia a la gracia. Entresacamos algunos ejemplos con los correspondientes sustantivos: leggiadria: gracia 263, 457; leggiadrio: gracioso 47, 75, 117, 261, 397, gentil y gracioso 421 (cf. también piacevole: gracioso 267, 279); vaghezza: graçia 129, 265. No podemos olvidar que la gracia era cualidad máxima en las criaturas de Castiglione y, aun sin extremar la influencia de éste, la presencia tanto de gracia como de su antónimo desgracia (267, por spiacevolezza) nos hace pensar en el Cortegiano y en su versión española.

Otra pregunta que se le ocurre a todo lector de traducciones del Galateo y que hemos considerado más a fondo a propósito de la adaptación de Gracián Dantisco, se refiere a un concepto central de la obra, el de maniere o belle maniere, o sea lo que en el español de hoy se llaman modales y en inglés (desde el siglo xvi) manners. Sin reproducir todas las interpretaciones de nuestro traductor (por ejemplo, maniere: trato 17 , trato y conversación 19), creo poder afirmar que, si

16 Piénsese en un título como De la civilité puérile, o en el de la obra de Nathaniel Walker, The refin'd courtier or a correction of several corrupt indecencies crept into civil conversation, Londres, 1663. 
NRFH, XV

bien no falta el empleo de manera sin más ("per dolce modo": "por su manera" 43), parece que maneras como "modales" no ha entrado en el vocabulario español de la época de Becerra. Si hubiera entrado no mostraría éste una clara tendencia a apoyar el término manera en otros más estrechamente relacionados con el ámbito de las costumbres ("manera en el tratar" 7, "la agradable y graçiosa manera que tienen en su trato y conuersaçion" 11 , "todos sus modos y maneras de conversar" 17).

La falta de un diccionario especial para los siglos xvr y xvn puede suplirse con la lectura atenta de traducciones de obras significativas. En el Galateo de Domingo de Becerra hallará el curioso lector muchas correspondencias e interpretaciones interesantes de las palabras claves de una tradición cortés que Della Casa contribuyó a propagar por Europa. En la traducción hallará también toda la materia doctrinal que Gracián Dantisco omite en su adaptación, y sobre todo esas máximas que encarecieron el Galateo para muchas generaciones de lectores ("[a los hombres hay que] acceptarlos, no por lo que realmente valen, sino como se haze con las monedas, por lo que corren" 91; "los hombres tienen tanta necesidad de llorar como de reír" 123; "condiçion es general de todos seguir de buena gana las pisadas de sus Señores" 195). No poca sabiduría, ya algo cínica, ya optimista, puede espigarse en las páginas del Galateo, traducido por Becerra para instrucción y pasatiempo de una sociedad cosmopolita a fines del siglo xvI.

Catholic University, Washington. 